\title{
RESPONSABILIDADE SOCIAL E INVESTIMENTO SOCIAL PRIVADO: ENTRE O DISCURSO E A EVIDENCIAÇÃO
}

\author{
SOCIAL RESPONSIBILITY AND PRIVATE SOCIAL INVESTMENT: \\ BETWEEN DISCOURSE AND DISCLOSURE
}

\author{
MARCO ANTONIO FIGUEIREDO MILANI FILHO \\ Professor Associado do Departamento de Contabilidade do Centro de Ciências Sociais Aplicadas e \\ Pesquisador do Núcleo de Estudos do Terceiro Setor da Universidade Presbiteriana Mackenzie \\ E-mail:mmilani@usp.br
}

\section{RESUMO}

Esta pesquisa objetivou investigar se as empresas que se declaram socialmente responsáveis divulgam informações financeiras específicas sobre os recursos gastos em benefício público (investimento social privado) e, também, verificar se há diferença significativa da dimensão desses gastos entre empresas cujos produtos estão associados a externalidades negativas e as organizações participantes do Îndice de Sustentabilidade Empresarial (ISE) da Bolsa de Valores de São Paulo (Bovespa). A amostra foi formada por 52 empresas, segregando-se em: 34 organizações participantes do ISE e 18 empresas das indústrias de fumo, bebidas alcoólicas e armas. Os dados foram obtidos dos relatórios anuais dos exercícios de 2005 e 2004, páginas eletrônicas e bảlanços sociais das respectivas empresas, do banco de dados eletrônicos da Bovespa e, ainda, de questionários enviados aos gestores cujas empresas não explicitavam, publicamente, seus projetos sociais. Os resultados apontaram que nem todas as organizações que declaram realizar investimentos sociais evidenciam tal fato. $\mathrm{Na}$ amostra, $11,8 \%$ das entidades componentes do ISE e $72,2 \%$ das organizações vinculadas a externalidades negativas, não divulgam informações financeiras sobre o valor de gastos sociais, gerando dúvidas sobre a existência ou a dimensão dos investimentos à comunidade. As duas únicas empresas de fumo (CTA Continental e Souza Cruz) que evidenciam informações, entretanto, destacam-se por apresentarem média de investimentos sociais maiores do que a das empresas do ISE, indicando que há incentivos específicos para tal comportamento.

Palavras-chaves: Responsabilidade social. Investimento social privado. Evidenciação. Externalidades negativas.

\section{ABSTRACT}

This study aims to investigate if companies that declare themselves socially responsible divulge specific financial information on resources spent in public benefit (private social investment) and, also, if the dimension of these expenses is significantly different between companies whose products are associated to negative externalities and the organizations members of the Corporate Sustainability Index (CSI) of the São Paulo Stock Exchange (Bovespa). The sample consisted of 52 companies, separated in: 34 CSI participant organizations and 18 companies from the tobacco, alcoholic beverages and arms industries. The data were obtained from annual reports (fiscal years 2005 and 2004), websites, social statements and the Bovespa electronic database. Questionnaires were sent to managers of companies that did not disclose their social projects. Although most of the companies declare themselves socially responsible, the results appointed that $11.8 \%$ of CSI companies and $72.2 \%$ of organizations associated with negative externalities do not divulge financial information on social expenses, generating doubts about the existence or the dimension of their investments in the community. Only two tobacco companies (CTA Continental and Souza Cruz) used to disclose social information. They stand out because they present higher average levels of social investments than CSI companies, suggesting that they have specific incentives for such behavior.

Keywords: Social responsibility. Private social investment. Disclosure. Negative externalities. 


\section{INTRODUÇÃO}

Nos últimos anos, é crescente a quantidade de empresas que informam, publicamente, a adoção de práticas socialmente responsáveis, ainda que não exista um consenso acadêmico e empresarial sobre a conceituação e a abrangência de Responsabilidade Social. Basicamente, tais práticas direcionam-se aos públicos interno e externo da organização, buscando atender aos interesses e expectativas dos diferentes stakeholders. Essas práticas, ainda, se relacionam aos conceitos de sustentabilidade e governança corporativa.

Os proprietários das empresas (as quais são apenas entidades legais) respondem, em última instância, pelo desempenho da organização. Nesse sentido, a adoção de práticas socialmente responsáveis liga-se aos interesses dos proprietários e insere-se no contexto estratégico empresarial de sobrevivência, rentabilidade e valor de mercado da organização.

Considerando-se os problemas de agência existentes entre propriedade e controle, os proprietários definem objetivos e estabelecem metas para os gerentes, além de acompanhá-los conforme os mecanismos disponíveis para reduzir a assimetria informacional entre as partes. Estruturas internas que propiciem instrumentos de governança eficazes aumentam a confiança do investidor externo. Práticas socialmente responsáveis, então, podem reduzir a assimetria de informações entre investidores e gestores, especialmente sob o enfoque da governança corporativa.

Assumindo que empresas sustentáveis geram valor para o acionista no longo prazo, pois, supostamente, estão mais preparadas para enfrentar riscos econômicos, sociais e ambientais, a Bolsa de Valores de São Paulo (Bovespa) lançou, em 2005, o índice de Sustentabilidade Empresarial (ISE), composto por empresas abertas, selecionadas por possuírem práticas de Responsabilidade Social sob os seguintes enfoques: econômico-financeiro, social, ambiental, governança corporativa e natureza dos produtos. Para o biênio 2006/2007, a carteira do ISE é formada por 34 empresas de diferentes setores.

Organizações relacionadas a externalidades negativas, como as indústrias de cigarro, bebidas alcoólicas e armas, apesar de legalmente estabelecidas e autorizadas a comercializarem bens e serviços sob controles específicos, são motivos de discussão quando também se declaram socialmente responsáveis e divulgam manter padrões éticos de comportamento com os públicos interno e externo. Com a imagem institucional vinculada a custos sociais, a adoção de práticas socialmente responsáveis poderia contribuir para a melhoria de percepção dessa imagem pelos públicos envolvidos ou, ainda, internalizar, sob a ótica econômica, parte das externalidades negativas.

Ações voltadas à satisfação de necessidades do público interno, como treinamento e benefícios a funcionários, convertem-se em investimentos no capital humano e tornam a empresa mais competitiva. Ações direcionadas a melhorar o relacionamento com determinados stakeholders externos, como fornecedores, favorecem a obtenção de melhores condições de aquisição e de pagamento pelos fatores produtivos, aumentando a competitividade da empresa. O cumprimento de obrigações legais, como o pagamento de tributos, evita penalizações à empresa e aos seus gestores. $O$ investimento em equipamentos de proteção ambiental evita multas por danos ao meio-ambiente e processos jurídicos de entidades ambientalistas. Todas essas medidas estão diretamente relacionadas com a sustentabilidade da organização e, supostamente, contribuem para melhorar os resultados futuros e aumentar o valor de mercado da empresa.

Para este estudo foram consideradas somente as ações destinadas à comunidade para efeito comparativo entre as empresas, pois tais ações são mais facilmente segregadas dos gastos operacionais das entidades e reflete um aspecto fundamental na avaliação do investimento social privado (que tem como característica o benefício público). Não foram considerados elementos qualitativos para essa comparação.

A principal motivação desta pesquisa foi descobrir a freqüência de empresas do ISE que se declaram socialmente responsáveis e promovem ações diretas à comunidade. Outra motivação foi verificar se os gastos em ações sociais das empresas produtoras de cigarro, bebidas alcoólicas e armas são, proporcionalmente, maiores que os das empresas componentes do ISE (consideradas referências de comportamento socialmente responsável entre as empresas abertas).

Espera-se que este trabalho exploratório contribua para a discussão acadêmica sobre o tema, considerando a carência de pesquisas empíricas brasileiras sobre investimentos sociais privados. Procura-se, ainda, incentivar novos estudos sobre a relação entre: gastos sociais de empresas, vantagem competitiva, externalidades negativas e sustentabilidade.

\section{RESPONSABILIDADE SOCIAL CORPORATIVA - RSC}

Desde a Revolução Industrial, o papel social das empresas privadas vem sendo debatido nos meios acadêmicos, empresariais e governamentais. Autores como Friedman (1962), McClaughry (1972), Hester (1973), Ramanathan (1976), Wood (1991), Waddock (2001), Fischer (2002),
Garriga e Mele (2004), Brown et al. (2006), entre muito outros, levantaram diversas questões sobre esse papel e sobre as responsabilidades inerentes às organizações.

$\mathrm{O}$ interesse empresarial em divulgar o comprometimento com práticas de responsabilidade Social Corporati- 
va (RSC) faz com que a quantidade de informações disponibilizadas publicamente aumente gradativamente, como demonstrado por Esrock e Leichty (1998), cuja pesquisa apontou que $82 \%$ das grandes empresas americanas tratavam, explicitamente, de questões sobre responsabilidade social em seus relatórios anuais.

Apesar da farta literatura existente, com indiscutível predominância de autores estrangeiros, não houve uma consolidação sobre o conceito de RSC, mas há aspectos genéricos que delineiam o seu significado.

Para o Instituto Ethos (2006), Responsabilidade Social Corporativa (ou Empresarial), integra o conjunto de interesses das empresas e de seus stakeholders, além de fomentar o desenvolvimento socioeconômico das comunidades do entorno. Para tanto, os tipos de relacionamento entre as partes envolvidas, formalizados contratualmente ou não, expressarão a complexidade de interesses e expectativas dos diferentes agentes e serão avaliados sob três dimensões (Tripple Bottom Line): econômica, social e ambiental.

As práticas socialmente responsáveis desenvolvemse, portanto, nos relacionamentos estabelecidos com os stakeholders, dentro da cadeia de negócios das empresas, de forma a gerar condições favoráveis para a sustentabilidade empresarial.

O caráter dinâmico da RSC faz com que se assemelhe a um processo ininterrupto de monitoramento do ambiente e das relações e não se fixe, estaticamente, em grupos específicos (BORGER, 2001; FISCHER, 2002). Esse dinamismo reflete o grau de adaptabilidade da empresa ante as condições do próprio mercado.
Brown et al. (2006), explorando os problemas de agência envolvidos nas decisões de se adotarem práticas de RSC, estimulam a reflexão sobre modelos de governança corporativa capazes de aliar o objetivo de maximização da riqueza dos acionistas com os interesses de gestores e outros stakeholders. Sob a perspectiva utilitarista, a promoção de práticas sociais podem favorecer os interesses de gestores e membros do conselho de administração, além de contribuir com a melhoria da percepção da imagem institucional da empresa. O aumento no valor da empresa decorreria da obtenção de vantagens competitivas.

O trabalho de Brown et al. (2006) constatou, também, que o volume das transferências diretas de recursos financeiros à comunidade depende do tamanho do conselho e das características de concentração acionária existentes. Conselhos menores e uma quantidade reduzida de blocos de acionistas tenderiam a ser mais receptivos às idéias de patrocínio de projetos sociais e doações a entidades filantrópicas.

Johns (2006), pesquisando as práticas de RSC de empresas fabricante de produtos nocivos à saúde, particularmente a indústria de tabaco, discute a situação paradoxal dessas empresas, que se declaram socialmente responsáveis apesar dos custos sociais gerados por seus produtos. Nesse sentido, o investimento social privado seria parte de um conjunto de medidas estratégicas de marketing para reduzir a rejeição popular à natureza do negócio e contribuir para influenciar os legisladores ante as leis e ações reguladoras contra o tabaco que afetariam negativamente seus resultados.

\section{DISCLOSURE SOCIAL}

A complexidade da economia moderna ampliou os grupos que têm interesses legítimos no desempenho das empresas e, dessa maneira, exige-se que as informações divulgadas por elas atendam a diferentes usuários, não somente investidores (HENDRIKSEN; VAN BREDA, 1999).

Ramanathan (1976) foi um dos precursores a tratar, sob a ótica contábil, a questão da Responsabilidade Social e a evidenciação dos impactos sociais gerados pelas empresas privadas. $\mathrm{O}$ autor levantou questões centrais para um arcabouço teórico da Contabilidade Social corporativa (diferente do conceito em Economia que trata dos agregados macroeconômicos) e estimulou o debate sobre as relações existentes entre empresa, mercado e comunidade. Ainda que alguns pontos de sua proposta conceitual merecessem ser revistos (ver TIPGOS, 1977 e BURTON, 1977), outros podem ser considerados atuais e relevantes, como a necessidade de mensuração, avaliação e comunicação dos eventos relacionados a diferentes stakeholders, prestação de contas (accountability) e a demonstração do valor econômico agregado à sociedade.

A divulgação pública de um conjunto de informações sobre o envolvimento da empresa com a comunidade, funcionários, meio-ambiente e benefícios dos produtos ofe- recidos é conhecido como Disclosure Social (ANDERSON; FRANKLE, 1980).

No Brasil, a maior parte das informações sobre as atividades sociais das empresas é divulgada de maneira voluntária, mas a simples divulgação de notícias em seus websites sobre a existência de políticas e programas sociais, sem a evidenciação dos fatos, não comprova o comprometimento nem dimensiona as ações sociais da organização junto aos diferentes públicos.

Para favorecer a redução da assimetria informacional entre a organização e seus stakeholders, alguns instrumentos de evidenciação e certificação são utilizados, como: NBR 16001 (Associação Brasileira de Normas Técnicas), GRI Sustainability Report (Global Reporting Initiative), SA 8000 (Social Accountability Institute), AA 1000 (Institute of Social and Ethical Accountability), Indicadores de Responsabilidade Social (Instituto Ethos), além do Balanço Social.

Ullmann (1985), após analisar diferentes pesquisas e correlacionar o nível de disclosure voluntário das informações sociais com a postura estratégica da empresa, a força de pressão dos stakeholders e os desempenhos econômico e social, destaca as seguintes situações: 
- o desempenho social é positivamente correlacionado com a força de pressão dos stakeholders;

- o desempenho social apresenta correlação indeterminada com desempenho econômico;

- o disclosure social é positivamente correlacionado com o desempenho social;

- o disclosure social apresenta correlação indeterminada com a postura estratégica.

O trabalho de Ulhman (1985) sinaliza que o desempenho social da empresa é mais influenciado pela pressão exercida por grupos de interesse do que pelo desempenho econômico e, ainda, que o disclosure social esteja diretamente relacionado com o desempenho social, ou seja, as empresas aumentem a quantidade de informações divulgadas voluntariamente quanto mais favoráveis forem os resultados sociais.

\subsection{Balanço Social}

O Balanço Social não é uma peça obrigatória, mas constitui-se num dos principais relatórios sobre as características da empresa e seu relacionamento com diferentes públicos, por isso é considerado relevante para a identificação e avaliação do envolvimento da organização com a Responsabilidade Social.

ludícibus et al. (2003) afirmam:

"O Balanço Social tem por objetivo demonstrar o resultado da interação da empresa com o meio em que está inserida. Possui quatro vertentes: o Balanço Ambiental, o Balanço de Recursos Humanos, Demonstração do Valor Adicionado e Benefícios e Contribuições à Sociedade em geral." (IUDíCIBUS et al., 2003, p. 33)

Para Tinoco (2001), Balanço Social é um instrumento gerencial que procura evidenciar, de forma transparente, informações sociais e econômicas do desempenho das entidades aos diferentes usuários.

Os principais modelos adotados pelas empresas brasileiras para a elaboração do Balanço Social são disponibilizados pelo Instituto Ethos e pelo Instituto Brasileiro de Análises Sociais e Econômicas (lbase). Ambos os modelos são estruturados para que as empresas divulguem informações relevantes sobre seus relacionamentos com os públicos interno e externo, servindo-se de dados financeiros e não-financeiros e pautando-se pelas dimensões da Tripple Bottom Line (econômica, social e ambiental).

Conforme afirma Santos (2003), o Balanço Social é elaborado sobre a base contábil de dados, demonstrando que a função social da Contabilidade extrapola a simples prestação de informações aos proprietários e credores, representando o elo de comunicação entre a entidade legal (empresa) e a sociedade que a envolve.

\subsection{Investimento Social Privado - ISP}

Investimento Social Privado (ISP) é um conceito que apresenta diferentes interpretações, mas é caracterizado, basicamente, pela transferência voluntária de recursos de empresas privadas para projetos sociais, ambientais e culturais de interesse público.

Segundo Fischer et al. (2005), no Brasil, o ISP é materializado em projetos sociais desenvolvidos a partir de parcerias ou alianças entre o Segundo e o Terceiro Setor. Sob essa perspectiva, as empresas direcionam recursos para organizações não-governamentais sem fins lucrativos para a promoção de determinada ação social.

Já para o Grupo de Instituto, Fundações e Empresas (GIFE, 2002), o ISP é caracterizado pelo direcionamento de recursos privados de pessoas jurídicas ou físicas para projetos e ações sociais, sem a necessidade de parceria ou alianças com organizações do Terceiro Setor, mas com o comprometimento de se monitorarem e avaliarem os projetos desenvolvidos para diferenciá-los de práticas assistencialistas. Nesse sentido, espera-se que o investidor social se envolva com as ações e os resultados proporcionados à comunidade.

Outros autores, como Brown et al. (2006), adotam uma conceituação mais abrangente e consideram que o ISP engloba, também, a transferência direta para entidades de assistência social na forma de doações, sem o comprometimento explícito de monitoramento de resultados. O conjunto dessas práticas vincula-se ao termo Filantropia Corporativa.

O ISP, entretanto, não se confunde com os recentes projetos de Parceria Público-Privada (PPP), cujos contratos prevêem retorno financeiro às empresas pelos investimentos realizados em obras de interesse público.

Contabilmente, investimentos e gastos possuem significados mais restritos do que sob a ótica de outras disciplinas acadêmicas. Para este trabalho, gasto social foi utilizado como sinônimo de investimento social.

\section{MÉTODO DA PESQUISA}

O objetivo geral desta pesquisa exploratória foi o de investigar se as empresas que se declaram socialmente responsáveis e financiadoras de projetos sociais divulgam informações financeiras específicas sobre os recursos gastos em benefício público, evidenciando o investimento social privado e contribuindo para reduzir a assimetria informacional entre a empresa e seus stakeholders. Procurou-se, ainda, verificar se há diferença significativa da dimensão dos investimentos sociais entre empresas com produtos associados a externalidades negativas e organizações participantes do Índice de Sustentabilidade Empresarial (ISE) da Bolsa de Valores de São Paulo (Bovespa).

A amostra foi composta pelas 34 empresas componentes do ISE e por 18 empresas representativas (participam, em conjunto, com mais de $90 \%$ dos mercados em que atuam) das indústrias de fumo, bebidas alcoólicas e armas. 
Por uma questão de conveniência, as empresas de bebidas alcoólicas foram restringidas às produtoras de cerveja. As empresas pesquisadas e seus setores de atuação estão relacionados nos Quadros 10 e 20.

Como métrica comparativa, utilizou-se a participação dos gastos em ações sociais no valor do resultado operacional das empresas.

$$
P G S=\frac{G S}{R O}
$$

em que:

PGS = participação dos gastos com ações sociais direcionados à comunidade;

GS = valor médio dos gastos sociais direcionados à comunidade nos exercícios de 2004 e 2005;

$R O=$ valor médio dos resultados operacionais da empresa obtidos nos exercícios de 2004 e 2005.

Optou-se por utilizar o resultado operacional como denominador considerando-se que ele também é utilizado

\begin{tabular}{|l|l|l|l|}
\hline \multicolumn{1}{|c|}{ Empresa } & \multicolumn{1}{|c|}{ Setor } & \multicolumn{1}{c|}{ Empresa } & \multicolumn{1}{c|}{ Setor } \\
Dasa & Análises e Diagnósticos & lochp-Maxion & Material de Transporte \\
Perdigão & Carnes e Derivados & Aracruz & Papel e Celulose \\
Celesc & Energia Elétrica & Suzano Papel & Papel e Celulose \\
Coelce & Energia Elétrica & VCP & Papel e Celulose \\
Copel & Energia Elétrica & Braskem & Petroquímicos \\
CPFL Energia & Energia Elétrica & Petrobras & Petroquímicos \\
Eletropaulo & Energia Elétrica & Suzano Petr & Petroquímicos \\
Energias BR & Energia Elétrica & Ultrapar & Petroquímicos \\
Tractebel & Energia Elétrica & Natura & Produtos de Uso Pessoal e Limpeza \\
CCR Rodovias & Exploração de Rodovias & Acesita & Serviços de locação \\
Bradesco & Intermediação Financeira & Arcelor & Siderurgia e Metalurgia \\
Banco do Brasil & Intermediação Financeira & Gerdau & Siderurgia e Metalurgia \\
Itaubanco & Intermediação Financeira & Gerdau Met & Siderurgia e Metalurgia \\
Itausa & Intermediação Financeira & ALL & Siderurgia e Metalurgia \\
Unibanco & Intermediação Financeira & GOL & Transporte Aéreo e Ferroviário \\
Embraer & Aeroespacial & TAM & Transporte Aéreo e Ferroviário \\
\hline & & \\
\hline
\end{tabular}

Quadro 1 Empresas e setores - ISE

\begin{tabular}{|l|l|l|}
\multicolumn{1}{|c|}{ Fumo } & Bebidas (Cerveja) & Armas e Munições \\
Alliance One Brasil & Ambev & Boito \\
Brasfumo & Baden Baden & CBC \\
CTA-Continental & Cerpa & Imbel \\
Intab & Cintra & Taurus \\
Philip Morris do & Kaiser & \\
Brasil & Schincariol & \\
Souza Cruz & & \\
Sudamax & & \\
Universal Leaf & & \\
\end{tabular}

Quadro 2 Empresas e setores associados a externalidades negativas 
como base de referência nos modelos atuais de balanço social.

Os dados foram coletados nos relatórios anuais, websites ou balanços sociais disponibilizados pelas empresas. Na ausência de informações públicas, as empresas foram contatadas através dos canais de comunicação eletrônica para atendimento ao consumidor ou ao investidor e receberam uma carta de apresentação, por correio eletrônico, com os objetivos da pesquisa e solicitando-Ihes as informações necessárias para este estudo.

Para a comparação de médias entre o grupo com 34 empresas do ISE e o grupo de 18 empresas associadas a externalidades negativas, optou-se pelo teste não-paramétrico de Mann-Whitney, uma vez que as condições para sua realização foram atendidas e sua aplicação é mais flexível que o teste paramétrico de médias para duas amostras (STEVENSON, 1981). Para as demais comparações de dados com o grupo do ISE, utilizou-se o teste de significância de uma amostra, em que foram utilizados como valores de referência as médias dos gastos sociais das empresas dos setores de Fumo, Bebidas Alcoólicas e Armas.

O programa estatístico utilizado para os cálculos foi o SPSS 11

Não foi objetivo desta pesquisa a divulgação isolada de dados das organizações pesquisadas, mas as empresas foram mencionadas quando necessário para esclarecimento de tópicos relacionados.

\section{APRESENTAC̣ÃO DOS DADOS}

\subsection{Envolvimento com Práticas de Responsabilidade Social}

A comunicação pública, pela empresa, de que há políticas e práticas relacionadas à Responsabilidade Social, supõe o envolvimento empresarial com a melhoria das relações com seus stakeholders. Na Tabela $1 \mathbf{0}$, é possível verificar a proporção de entidades (agrupadas) que comunicam possuir tal envolvimento, conforme seus relatórios anuais ou websites:

As organizações componentes do ISE e todas as empresas do setor de Fumo declaram seguir políticas ou promoverem ações relacionadas à Responsabilidade Social. Apenas $50 \%$ do grupo de 4 empresas produtoras de armas (Imbel e Taurus), assim como 50\% das 6 produtoras de bebidas alcoólicas/cerveja (Ambev, Baden Baden e Schincariol), declaram-se envolvidas com práticas socialmente responsáveis. A Tabela 1 não mostra o grau de envolvimento empresarial com as práticas de Responsabilidade Social, mas permite identificar as empresas que consideram relevante essa divulgação.

\subsection{Promoção de Ações Sociais}

Considerando que, conceitualmente, Responsabilidade Social implica no atendimento de necessidades dos públicos interno e externo, atender somente a um desses públicos torna parcial o envolvimento e o comprometi- mento social da empresa. A realização de ações sociais, portanto, deveria ser uma das práticas regulares das entidades para serem caracterizadas como socialmente responsáveis.

A proporção de organizações que evidenciam, financeiramente, a promoção e o apoio de ações direcionadas à comunidade é apresentada na Tabela 20

O fato de não haver a evidenciação não exclui a possibilidade de que ações sociais sejam realizadas, mas uma vez que não são evidenciadas, pressupõe-se a inexistência Gráfico 10.

Dentre as componentes do ISE, 11,8\% (4 empresas) não informaram desenvolver projetos com a comunidade ou transferir recursos para organizações do Terceiro Setor. Contatadas pelos canais de atendimento ao consumidor ou ao investidor, 2 gestores de empresas afirmaram apoiar projetos sociais mas não souberam informar o gasto médio dessas ações, e as outras 2 empresas não colaboraram com esta pesquisa.

Apesar de 100\% das produtoras de fumo declararem em seus websites que atuam diretamente nas comunidades relacionadas e apóiam projetos sociais, apenas $25 \%$ delas (CTA Continental e Souza Cruz) forneceram evidências financeiras sobre o investimento social privado, ou seja, $75 \%$ das entidades analisadas desse setor divulgaram informações que desenvolvem projetos para

Tabela 1 || Empresas que comunicam envolvimento com práticas de Responsabilidade Social

\begin{tabular}{l|c|c|c|c}
\hline \multicolumn{1}{|c|}{ Grupos } & Empresas que comunicam & Part. & Empresas que não comunicam & Part. \\
\hline ISE & 34 & $100,0 \%$ & 0 & $0,0 \%$ \\
Fumo & 8 & $100,0 \%$ & 0 & $0,0 \%$ \\
Armas e Munições & 2 & $50,0 \%$ & 2 & $50,0 \%$ \\
Bebidas Alcoólicas (cerveja) & 3 & $50,0 \%$ & 3 & $50,0 \%$
\end{tabular}


Tabela 2 Evidenciação de Ações Sociais

\begin{tabular}{|c|c|c|c|c|c|c|}
\hline Setores & $\begin{array}{l}\text { Qtde de } \\
\text { empresas }\end{array}$ & $\begin{array}{l}\text { Com evidências } \\
\text { de ações sociais }\end{array}$ & Part. & $\begin{array}{l}\text { Sem evidências } \\
\text { de ações sociais }\end{array}$ & Part. & Total \\
\hline 1 Aeroespacial & 1 & 1 & $100,0 \%$ & 0 & $0,0 \%$ & \\
\hline 2 Análises e Diagnósticos & 1 & 0 & $0,0 \%$ & 1 & $100,0 \%$ & \\
\hline 3 Carnes e Derivados & 1 & 1 & $100,0 \%$ & 0 & $0,0 \%$ & \\
\hline 4 Energia Elétrica & 8 & 8 & $100,0 \%$ & 0 & $0,0 \%$ & \\
\hline 5 Exploração de Rodovias & 1 & 1 & $100,0 \%$ & 0 & $0,0 \%$ & \\
\hline 6 Intermediação Financeira & 5 & 5 & $100,0 \%$ & 0 & $0,0 \%$ & \\
\hline 7 Material de Transporte & 1 & 1 & $100,0 \%$ & 0 & $0,0 \%$ & \\
\hline 8 Papel e Celulose & 3 & 3 & $100,0 \%$ & 0 & $0,0 \%$ & \\
\hline 9 Petroquímicos & 4 & 4 & $100,0 \%$ & 0 & $0,0 \%$ & \\
\hline 10 Produtos de Uso Pessoal & 1 & 1 & $100,0 \%$ & 0 & $0,0 \%$ & \\
\hline 11 Serviços de locação & 1 & 0 & $0,0 \%$ & 1 & $100,0 \%$ & \\
\hline 12 Siderurgia e Metalurgia & 4 & 3 & $75,0 \%$ & 1 & $25,0 \%$ & \\
\hline 13 Transporte Aéreo e Ferroviário & 3 & 2 & $66,7 \%$ & 1 & $33,3 \%$ & \\
\hline Total (1) & 34 & 30 & $88,2 \%$ & 4 & $11,8 \%$ & $100 \%$ \\
\hline 1 Fumo & 8 & 2 & $25,0 \%$ & 6 & $75,0 \%$ & \\
\hline 2 Bebidas Alcoólicas (cerveja) & 6 & 2 & $33,3 \%$ & 4 & $66,7 \%$ & \\
\hline 3 Armas e Munições & 4 & 1 & $25,0 \%$ & 3 & $75,0 \%$ & \\
\hline Total (2) & 18 & 5 & $27,8 \%$ & 13 & $72,2 \%$ & $100 \%$ \\
\hline
\end{tabular}

Fonte: Elaborada pelo autor

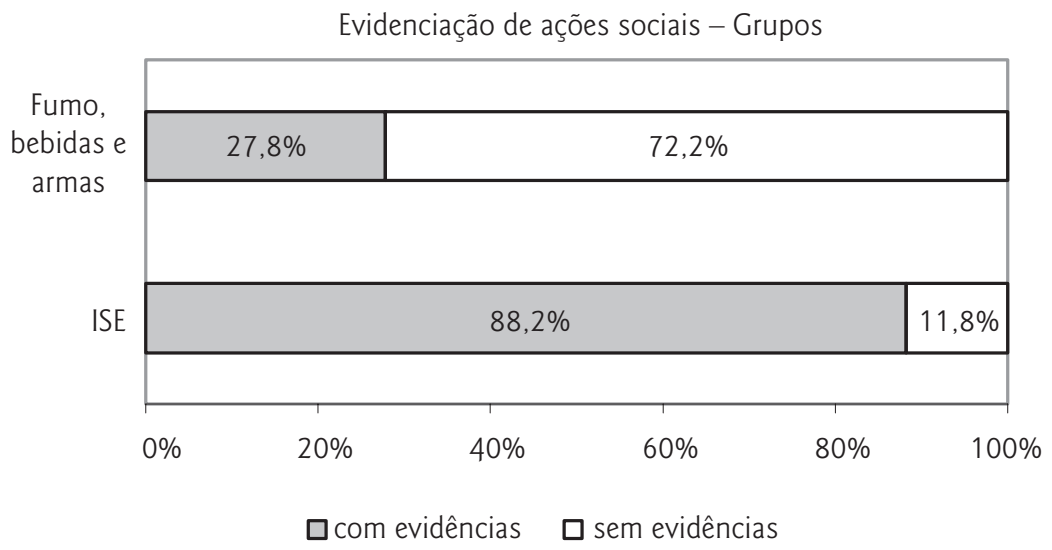

Gráfico 1 Evidenciação de Ações Sociais

a comunidade, mas não apresentaram evidências que permitam o devido dimensionamento dessas ações. As 6 entidades sem ações sociais evidenciadas foram contatadas, mas nenhuma manifestou-se sobre a ausência de informações.

Dentre as 4 empresas do setor de Armas, apenas uma (Imbel) promove e evidencia ações para a comunidade, especificamente nas áreas de educação e assistência social. As outras 3 pesquisadas não disponibilizaram informações.

Também com baixa participação, apenas 33,3\% das empresas do setor de Bebidas Alcoólicas (Ambev e Schincariol) oferecem informações sobre a promoção de ações sociais.

Na amostra, 27,8\% do grupo das empresas de fumo, cerveja e armas evidenciaram ações sociais, ante 88,2\% das empresas do ISE.

$\mathrm{Na}$ Tabela $3 \bullet$, são apresentadas as médias de gastos sociais por setores no biênio 2004-2005.

A média de gastos entre as 30 empresas do ISE que evidenciaram investimentos sociais no período, foi de $1,22 \%$ sobre 
Tabela 3 | Divulgação de Ações Sociais - ISE

\begin{tabular}{|c|c|c|c|c|}
\hline \multicolumn{5}{|c|}{ G.Sociais/Res.Op. } \\
\hline Setores/ISE & Qtde de Empresas & 2005 & 2004 & média \\
\hline Intermediação Financeira & 5 & $2,35 \%$ & $1,88 \%$ & $2,12 \%$ \\
\hline Petroquímicos & 4 & $1,64 \%$ & $1,49 \%$ & $1,56 \%$ \\
\hline Aeroespacial & 1 & $1,55 \%$ & $1,26 \%$ & $1,40 \%$ \\
\hline Energia Elétrica & 8 & $1,20 \%$ & $1,46 \%$ & $1,33 \%$ \\
\hline Produtos de Uso Pessoal & 1 & $1,08 \%$ & $1,08 \%$ & $1,08 \%$ \\
\hline Exploração de Rodovias & 1 & $1,01 \%$ & $1,01 \%$ & $1,01 \%$ \\
\hline Transporte Aéreo e Ferroviário & 2 & $0,71 \%$ & $1,30 \%$ & $1,00 \%$ \\
\hline Siderurgia e Metalurgia & 3 & $0,49 \%$ & $0,88 \%$ & $0,69 \%$ \\
\hline Papel e Celulose & 3 & $0,36 \%$ & $0,77 \%$ & $0,56 \%$ \\
\hline Material de Transporte & 1 & $0,47 \%$ & $0,30 \%$ & $0,39 \%$ \\
\hline Carnes e Derivados & 1 & $0,44 \%$ & $0,30 \%$ & $0,37 \%$ \\
\hline Total (empresas ISE com ações sociais) & 30 & & & \\
\hline Média (setores com ações sociais) & & $1,03 \%$ & $1,06 \%$ & $1,05 \%$ \\
\hline Desvio padrão & & $0,63 \%$ & $0,49 \%$ & $0,54 \%$ \\
\hline Média (30 empresas) & & $1,21 \%$ & $1,24 \%$ & $1,22 \%$ \\
\hline Desvio padrão & & $1,42 \%$ & $1,14 \%$ & $1,23 \%$ \\
\hline Análises e Diagnósticos & 1 & $0,00 \%$ & $0,00 \%$ & $0,00 \%$ \\
\hline Serviços de locação & 1 & $0,00 \%$ & $0,00 \%$ & $0,00 \%$ \\
\hline Siderurgia e Metalurgia & 1 & $0,00 \%$ & $0,00 \%$ & $0,00 \%$ \\
\hline Transporte Aéreo e Ferroviário & 1 & $0,00 \%$ & $0,00 \%$ & $0,00 \%$ \\
\hline Total (empresas ISE sem ações sociais) & 4 & & & \\
\hline Total ISE & 34 & & & \\
\hline Média (todos os setores) & & $0,75 \%$ & $0,78 \%$ & $0,77 \%$ \\
\hline Desvio padrão & & $0,71 \%$ & $0,64 \%$ & $0,66 \%$ \\
\hline Média (34 empresas) & & $1,07 \%$ & $1,09 \%$ & $1,08 \%$ \\
\hline Desvio padrão & & $1,37 \%$ & $1,12 \%$ & $1,20 \%$ \\
\hline
\end{tabular}

Fonte: Elaborada pelo autor

o resultado operacional. Considerando-se as 4 empresas que não evidenciaram esse tipo de investimento, a média de gastos por empresa foi de $1,08 \%$ sobre o resultado operacional.

O setor que mais investiu socialmente no período foi o de Intermediação Financeira, com média de 2,12\% por empresa. Os setores de Análise e Diagnóstico (representado pela Dasa) e Serviços de Locação (representado pela Localiza) não apresentaram evidências financeiras de gastos sociais.

A Tabela $4 \bullet$ permite verificar que todos os setores associados a externalidades negativas possuem empresas que investem socialmente. A média de gastos sociais do grupo formado pelos 3 setores (fumo, bebidas alcoólicas e armas) é de 0,69\% sobre o resultado operacional.

Dentre as empresas que evidenciaram ações à comu- nidade, as 2 entidades do setor de Fumo (CTA Continental e Souza Cruz) destacaram-se com média de gastos de $2,61 \%$, ante a média de $1,27 \%$ das produtoras de cerveja (Ambev e Schincariol). A Imbel, única representante do setor de Armas a evidenciar seus gastos sociais, apresentou uma participação média de 0,29\% sobre o resultado operacional.

\subsection{Testes Comparativos}

5.3.1 Comparação entre amostras independentes: Grupo ISE X Grupo Fumo, Bebidas e Armas

Para a comparação do grupo formado pelas 34 empresas do ISE com o grupo de 18 empresas associadas a externalidade negativas, utilizou-se o teste não-paramétrico de 
Tabela 4 | Divulgação de Ações Sociais - Setores de Fumo, Bebidas Alcoólicas e Armas

\begin{tabular}{|c|c|c|c|c|}
\hline \multicolumn{5}{|c|}{ G.Sociais/Res.Op. } \\
\hline Setores/ISE & Qtde de Empresas & 2005 & 2004 & média \\
\hline Fumo & 2 & $3,10 \%$ & $2,13 \%$ & $2,61 \%$ \\
\hline Bebidas Alcoólicas (cerveja) & 2 & $1,18 \%$ & $1,37 \%$ & $1,27 \%$ \\
\hline Armas e Munições & 1 & $0,26 \%$ & $0,31 \%$ & $0,29 \%$ \\
\hline Total (empresas com ações sociais) & 5 & & & \\
\hline Média (setores com ações sociais) & & $1,51 \%$ & $1,27 \%$ & $1,39 \%$ \\
\hline Desvio padrão & & $1,45 \%$ & $0,91 \%$ & $1,17 \%$ \\
\hline Média (5 empresas) & & $1,76 \%$ & $1,46 \%$ & $1,61 \%$ \\
\hline Desvio padrão & & $1,55 \%$ & $0,84 \%$ & $1,18 \%$ \\
\hline Fumo & 6 & $0,00 \%$ & $0,00 \%$ & $0,00 \%$ \\
\hline Bebidas Alcoólicas (cerveja) & 4 & $0,00 \%$ & $0,00 \%$ & $0,00 \%$ \\
\hline Armas e Munições & 3 & $0,00 \%$ & $0,00 \%$ & $0,00 \%$ \\
\hline Total (empresas sem ações sociais) & 13 & & & \\
\hline Total de empresas & 18 & & & \\
\hline Média (3 setores) & & $0,76 \%$ & $0,63 \%$ & $0,69 \%$ \\
\hline Desvio padrão & & $1,23 \%$ & $0,90 \%$ & $1,06 \%$ \\
\hline Média (18 empresas) & & $0,49 \%$ & $0,41 \%$ & $0,45 \%$ \\
\hline Desvio padrão & & $1,11 \%$ & $0,78 \%$ & $0,94 \%$ \\
\hline
\end{tabular}

Mann-Whitney, com a hipótese nula $\left(\mathrm{H}_{0}\right)$ de que os grupos não possuem diferença significativa entre os gastos sociais

Descriptive Statistics

\begin{tabular}{l|c|c|c|c|c} 
& $\mathbf{N}$ & Mean & Std. Deviation & Minimum & Maximum \\
EMPR & 52 &, 8607 & 1,14848 &, 00 & 5,21 \\
EXTERN & 52 &, 35 &, 480 & 0 & 1
\end{tabular}

Descriptive Statistics

\begin{tabular}{|c|c|c|c|}
\hline EXTERN & N & $\begin{array}{c}\text { Mean } \\
\text { Rank }\end{array}$ & $\begin{array}{c}\text { Sum of } \\
\text { Ranks }\end{array}$ \\
\hline EMPR 0 & 34 & 31,38 & 1067,00 \\
1 & 18 & 17,28 & 311,00 \\
Total & 52 & & \\
\hline
\end{tabular}

Test Statistics

\begin{tabular}{l|r} 
& \multicolumn{1}{|c|}{ EMPR } \\
Mann-Whitney U & 140,000 \\
Wilcoxon W & 311,000 \\
Z & $-3,250$ \\
Asymp. Sig. (2-tailed) &, 001 \\
\hline
\end{tabular}

a. Grouping Variable: EXTERN

médios. Os seguintes resultados foram obtidos:

Considerando o valor de significância, pode-se afirmar, com 95\% de confiança, que há diferenças significativas entre os grupos analisados, rejeitando-se $\mathrm{H}_{0}$. Assim, os valores gastos em ações sociais pelo grupo das 18 empresas de fumo, bebidas alcoólicas (cerveja) e armas, proporcionalmente aos respectivos resultados operacionais, são significativamente diferentes (nesse caso, inferiores) aos valores do grupo das empresas do ISE.

\subsubsection{Teste de Significância: Grupo ISE X média das Empresas do Setor de Fumo}

Hipótese nula $\left(\mathrm{H}_{0}\right)$ : não há diferença significativa entre a média de gastos sociais do grupo ISE (34 empresas) e a média $(0,65 \%)$ de gastos sociais do setor de Fumo (8 
One-Sample Test

\begin{tabular}{|c|c|c|c|c|c|c|}
\hline & \multicolumn{6}{|c|}{ Test Value $=0.65$} \\
\hline & \multirow[t]{2}{*}{$t$} & \multirow[t]{2}{*}{ df } & \multirow[t]{2}{*}{ Sig. (2-tailed) } & \multirow{2}{*}{$\begin{array}{c}\text { Mean } \\
\text { Difference }\end{array}$} & \multicolumn{2}{|c|}{$\begin{array}{c}95 \% \text { Confidence Interval } \\
\text { of the Difference }\end{array}$} \\
\hline & & & & & Lower & Upper \\
\hline ISE_34 & 2,086 & 33 & ,045 & 4298 &, 0106 & 8489 \\
\hline
\end{tabular}

empresas)

Conforme o resultado observado, pode-se afirmar, com $95 \%$ de confiança, de que há diferença significativa entre as médias comparadas, rejeitando-se $\mathrm{H}_{0}$. Assim, os valores gastos em ações sociais pelo grupo ISE, proporcionalmente aos respectivos resultados operacionais, são significativamente diferentes (nesse caso, superiores) aos valores do grupo de 8 empresas de fumo.

\subsubsection{Teste de significância entre empresas com ações sociais: ISE $X$ Setor de Fumo}

Hipótese nula $\left(\mathrm{H}_{0}\right)$ : o valor médio dos gastos sociais das 30 empresas do ISE que evidenciam ações à comunidade não difere, significativamente, da média $(2,61 \%)$ dos gastos sociais das 2 empresas do setor de Fumo que tam-

One-Sample Test

\begin{tabular}{c|c|c|c|c|c|c}
\hline & \multicolumn{7}{|c}{ Test Value = 2.61 } \\
\cline { 5 - 7 } & $\mathbf{t}$ & df & Sig. (2-tailed) & $\begin{array}{c}\text { Mean } \\
\text { Difference }\end{array}$ & $\begin{array}{c}\text { 95\% Confidence Interval } \\
\text { of the Difference }\end{array}$ \\
\cline { 5 - 7 } & & & $-1,3863$ & $-1,8375$ &,- 9351 \\
\hline
\end{tabular}

bém evidenciam seus gastos sociais.

Conforme observado, o resultado do teste permite afirmar que há diferença significativa entre as médias, rejeitando-se $\mathrm{H}_{0}$. Os valores proporcionais gastos em ações sociais pelas empresas do ISE são, significativamente, diferentes (nesse caso, inferiores) da média das empresas do setor de Fumo (CTA Continental e Souza Cruz) que também evidenciam investimentos sociais.

\subsubsection{Teste de Significância: Grupo ISE X média das empresas do Setor de Bebidas}

Hipótese nula $\left(\mathrm{H}_{0}\right)$ : a média de gastos sociais do grupo ISE (34 empresas) difere, significativamente, da média

One-Sample Test

\begin{tabular}{|c|c|c|c|c|c|c|}
\hline & \multicolumn{6}{|c|}{ Test Value $=0.4233$} \\
\hline & \multirow[t]{2}{*}{$\mathbf{t}$} & \multirow[t]{2}{*}{ df } & \multirow[t]{2}{*}{ Sig. (2-tailed) } & \multirow{2}{*}{$\begin{array}{c}\text { Mean } \\
\text { Difference }\end{array}$} & \multicolumn{2}{|c|}{$\begin{array}{c}95 \% \text { Confidence Interval } \\
\text { of the Difference }\end{array}$} \\
\hline & & & & & Lower & Upper \\
\hline ISE_34 & 3,186 & 33 &, 003 & ,6565 & 2373 & 1,0756 \\
\hline
\end{tabular}

$(0,42 \%)$ das 6 empresas do setor de Bebidas.

Conforme o resultado observado, pode-se rejeitar $\mathrm{H}_{0}$, com $95 \%$ de confiança. Assim, a média dos valores gastos em ações sociais pelo grupo de 34 empresas do ISE, proporcionalmente aos respectivos resultados operacionais, são significativamente diferentes (nesse caso, superiores), aos valores do grupo das 6 empresas do setor de Bebidas.

\subsubsection{Teste de significância entre empresas} com ações sociais: ISE X Setor de Bebidas

Hipótese nula $\left(\mathrm{H}_{0}\right)$ : o valor médio dos gastos sociais das 30 empresas do ISE que evidenciam ações à comunidade não difere, significativamente, do valor médio $(1,27 \%)$ dos gastos sociais das 2 empresas do setor de Bebidas que 
One-Sample Test

\begin{tabular}{|c|c|c|c|c|c|c|}
\hline & \multicolumn{6}{|c|}{ Test Value $=1.27$} \\
\hline & \multirow[t]{2}{*}{$\mathbf{t}$} & \multirow[t]{2}{*}{ df } & \multirow[t]{2}{*}{ Sig. (2-tailed) } & \multirow{2}{*}{$\begin{array}{c}\text { Mean } \\
\text { Difference }\end{array}$} & \multicolumn{2}{|c|}{$\begin{array}{c}95 \% \text { Confidence Interval } \\
\text { of the Difference }\end{array}$} \\
\hline & & & & & Lower & Upper \\
\hline ISE_30 &,- 210 & 29 & 835 &,- 0463 &,- 4975 & ,4049 \\
\hline
\end{tabular}

também evidenciam ações sociais.

Conforme observado, o resultado do teste não permite afirmar que há diferença significativa entre a média do grupo ISE e o valor de referência, aceitando-se $\mathrm{H}_{0}$. Os valores proporcionais gastos em ações sociais pelas empresas do setor de Bebidas (Ambev e Schincariol) não apresentam diferenças significativas com a média das empresas do ISE que também evidenciam investimentos sociais à comunidade.

\subsubsection{Teste de Significância: Grupo ISE X média das empresas do Setor de Armas}

Hipótese nula $\left(\mathrm{H}_{0}\right)$ : a média de gastos sociais do grupo ISE (34 empresas) não difere, significativamente, da média $(0,07 \%)$ das empresas do setor de Armas (4

One-Sample Test

\begin{tabular}{|c|c|c|c|c|c|c|}
\hline & \multicolumn{6}{|c|}{ Test Value $=0.07$} \\
\hline & \multirow[t]{2}{*}{$\mathbf{t}$} & \multirow[t]{2}{*}{ df } & \multirow[t]{2}{*}{ Sig. (2-tailed) } & \multirow{2}{*}{$\begin{array}{c}\text { Mean } \\
\text { Difference }\end{array}$} & \multicolumn{2}{|c|}{$\begin{array}{c}95 \% \text { Confidence Interval } \\
\text { of the Difference }\end{array}$} \\
\hline & & & & & Lower & Upper \\
\hline ISE_34 & 4,901 & 33 & ,000 & 1,0098 & ,5906 & 1,4289 \\
\hline
\end{tabular}

empresas).

Conforme o nível de significância apresentado, podese afirmar que há diferença significativa entre os valores comparados, rejeitando-se $\mathrm{H}_{0}$. Assim, os valores gastos em ações sociais pelo grupo das 34 empresas do ISE, proporcionalmente aos respectivos resultados operacionais, são significativamente diferentes (nesse caso, superiores) à média das 4 empresas do grupo de armas.

\subsubsection{Teste de significância entre empresas com ações sociais: ISE X Setor de Armas}

Hipótese nula $\left(\mathrm{H}_{0}\right)$ : o valor médio dos gastos sociais das 30 empresas do ISE que evidenciam ações à comunidade não difere, significativamente, do valor médio $(0,29 \%)$ da empresa do setor de Armas que também evidencia seus

One-Sample Test

\begin{tabular}{|c|c|c|c|c|c|c|}
\hline & \multicolumn{6}{|c|}{ Test Value $=0.29$} \\
\hline & \multirow[t]{2}{*}{$\mathbf{t}$} & \multirow[t]{2}{*}{ df } & \multirow[t]{2}{*}{ Sig. (2-tailed) } & \multirow{2}{*}{$\begin{array}{c}\text { Mean } \\
\text { Difference }\end{array}$} & \multicolumn{2}{|c|}{$\begin{array}{c}95 \% \text { Confidence Interval } \\
\text { of the Difference }\end{array}$} \\
\hline & & & & & Lower & Upper \\
\hline ISE_30 & 4,232 & 29 & ,000 & ,9337 & ,4825 & 1,3849 \\
\hline
\end{tabular}

gastos sociais.

Pode-se afirmar, conforme observado, que há diferença significativa entre a média do grupo ISE e o valor de referência, rejeitando-se $\mathrm{H}_{0}$. Os valores proporcionais gastos em ações sociais pelas empresas do ISE são significativamente diferentes (nesse caso, superiores) da média da empresa do setor 


\section{CONCLUSÃO}

Responsabilidade Social é um tema cada vez mais presente nos relatórios anuais e páginas eletrônicas das empresas no Brasil e envolve, basicamente, o aprimoramento das relações entre a organização e seus stakeholders de forma a criar condições favoráveis para o crescimento empresarial sustentável e contribuir para o desenvolvimento sob os enfoques sociais e ambientais. Nem todas as empresas que se declaram socialmente responsáveis, entretanto, apresentam evidências da dimensão financeira de seus esforços nesse sentido. Nesta pesquisa, constatou-se que 100\% das 34 empresas do ISE declaram-se socialmente responsáveis, mas $11,8 \%$ delas não apresentam evidências financeiras sobre investimentos sociais realizados no biênio 2004-2005.

As empresas associadas a externalidades negativas possuem, em seu conjunto, relevante participação de mercado (participação total de mercado superior a $90 \%$ nos setores de Fumo, Bebidas Alcoólicas/Cerveja e Armas) e verificouse que $100 \%$ das 8 organizações do setor de Fumo, 50\% das 6 produtoras de cerveja e $50 \%$ das 4 empresas do setor de Armas declaram estar comprometidas com práticas de responsabilidade Social, mas somente as seguintes entidades evidenciaram investimentos sociais: CTA Continental e Souza Cruz (fumo); Ambev e Schincariol (bebidas alcoólicas) e Imbel (armas).

O valor médio de gastos sociais das empresas do ISE foi de $1,08 \%$ sobre os respectivos resultados operacionais. Destacam-se as entidades do setor de Intermediação Financeira com a maior média $(2,12 \%)$, seguidas pelas organizações do setor de Petroquímicos (1,56\%).

Os investimentos sociais das 18 empresas (fumo, bebidas alcoólicas e armas) apresentaram um valor médio de $0,45 \%$, significativamente menor que a média obtida pelo grupo do ISE. Todavia, ao se compararem, somente, os dados das empresas que evidenciaram ações sociais, há diferenças relevantes nos resultados.

O valor médio $(2,61 \%)$ das empresas do setor de Fumo que evidenciaram investimentos sociais (CTA Continental e Souza Cruz) é superior, significativamente, ao valor de $1,22 \%$ das 30 empresas do ISE que também dimensionaram seus gastos sociais. Com relação às empresas de cerveja (Ambev e Schincariol), que apresentaram uma média de gastos sociais de $1,27 \%$ sobre os resultados operacio- nais, os testes não indicaram haver diferenças significativas com a média de gastos sociais de 30 empresas do ISE. O valor médio das ações sociais $(0,29 \%)$ da Imbel (armas) foi proporcionalmente menor que o de 30 empresas do ISE.

Examinando-se o fato de que os gastos em ações sociais das empresas de fumo (CTA Continental e Souza Cruz) foram, proporcionalmente, maiores que a média das empresas do ISE, supõe-se a existência de incentivos específicos para tal comportamento e sugere-se a validade da afirmação de Johns (2005), a qual vincula o investimento social dessas empresas como parte de um conjunto de medidas estratégicas de marketing. Não foi objeto deste estudo verificar se as empresas de tabaco que não evidenciam ações sociais assumem um comportamento oportunista denominado free-rider (efeito carona).

Por outro lado, o baixo valor investido socialmente pelas produtoras de armas indica não haver os mesmos estímulos da indústria do fumo. Baseando-se na pesquisa de Ullmann (1985), pode-se supor que as empresas que não evidenciam ações sociais não sofrem pressões de grupos de interesse e/ou não apresentam desempenho social satisfatório, fazendo com o nível de divulgação das informações sociais (disclosure social) também seja baixo.

Considerando-se que, dentre as práticas de Responsabilidade Social destacam-se as ações direcionadas à comunidade, pode-se questionar a pertinência de se classificar empresas como socialmente responsáveis quando essas não evidenciam investimentos sociais. Isso não significa, necessariamente, que devido ao fato de não haver mensuração e divulgação de ações sociais a empresa não possua políticas e práticas nesse sentido. Porém, quando as organizações apresentam reduzidos níveis de disclosure social, gera-se assimetria informacional entre a empresa e suas diferentes partes relacionadas, colocando-se em dúvida o grau de comprometimento social corporativo.

Para futuras pesquisas, sugere-se explorar o grau de investimento social privado entre empresas cujos produtos são, predominantemente, exportados e aquelas cujo mercado consumidor é nacional, para se verificar a suposição de que quanto menor o envolvimento com o mercado local, menor será o investimento social empresarial.

\section{Referências}

ANDERSON, J. C.; FRANKLE, A. W. Voluntary social reporting: an iso-beta portfolio analysis. The Accounting Review, v. 55, n. 3, p. 467-479, July, 1980.

ASSOCIAÇÃO BRASILEIRA DE NORMAS. TÉCNICAS - ABNT. NBR 16001: responsabilidade social, sistemas da gestão e requisitos. Rio de Janeiro: ABNT, 2004.

BOLSA DE VALORES DE SÃO PAULO - BOVESPA. Índice de sustentabilidade empresarial. Disponível em: <http://www.bovespa.com. br/emboacompanhia/>. Acesso em: 12 dez. 2006. 
BORGER, F. H. Responsabilidade social: efeitos da atuação social na dinâmica empresarial. 2001. Tese (Doutorado em Administração) - Faculdade de Economia, Administração e Contabilidade, Universidade de São Paulo.

BROWN, W. et al. Corporate philanthropic practices. Journal of Corporate Finance, Amsterdam: Elsevier, v. 12, n. 5, p. 855-877, 2006. BURTON, E. J. Toward a theory of corporate social accounting: a comment. The Accounting Review, v. 52, n. 4, p. 971-976, October, 1977. ESROCK, S. L.; LEICHTY, G. B. Social responsibility and corporate web pages: self-presentation or agenda-setting? Public Relations Review, Cambridge: Elsevier, v. 24, n. 3, p. 305-319, 1998.

FISCHER, R. M. O desafio da colaboração: práticas de responsabilidade social entre empresas e o terceiro setor. São Paulo: Gente, 2002.

FISCHER, R. M. et al. Sustentabilidade sócio-ambiental através de alianças estratégicas intersetoriais. In: CONFERENCIA LATINOAMERICANA Y DEL CARIBE, 5., 2005, Lima: ISTR, Universidad Ricardo Palma, 2005, p. 1-16.

FRIEDMAN, M. Capitalism and freedom. Chicago: University of Chicago Press, 1962.

GARRIGA, E.; MELE, D. Corporate social responsibility theories: mapping the territory. Journal of Business Ethics, v. 9, p. 51-71, 20.04. GLOBAL REPORTING INITIATIVE - GRI. Sustainability report. Disponível em: <http://www.globalreporting.org > Acesso em: 18 dez. 2006.

GRUPO DE INSTITUTOS FUNDAÇÕES E EMPRESAS - GIFE. Guia GIFE de investimento social privado. São Paulo: GIFE; 2002.

HENDRIKSEN; E. S.; VAN BREDA, M. Teoria da contabilidade. São Paulo: Atlas, 1999.

HESTER, J. M. Social responsibility of organisations in a free society. In: NADER, R. (ed.). Corporate power in America. New York: Grossman, 1973.

INSTITUTE OF SOCIAL AND ETHICAL ACCOUNTABILITY. AA 1000 Series of standards. Disponível em: <http://www.accountability21. net/aa1000/default.asp $>$. Acesso em: 16 dez. 2006.

INSTITUTO BRASILEIRO DE ANÁLISES ECONÔMICAS E SOCIAIS - IBASE. Balanço social. Disponível em: <http://www.ibase.org br/index.php >. Acesso em: 16 dez. 2006.

INSTITUTO ETHOS DE EMPRESAS E RESPONSABILIDADE SOCIAL - ETHOS. Responsabilidade social empresarial nos processos gerenciais e nas cadeias de valor. São Paulo: Ethos, 2006

IUDÍCIBUS, S. et al. Manual de contabilidade das sociedades por ações. 6. ed. São Paulo: Atlas, 2001.

JOHNS, P. Responsabilidade social empresarial: a nova face da indústria do tabaco. Disponível em: <http://www.tabacozero.net/uploads/458_ RSE_NovaFaceTabaco.pdf $>$. Acesso em: 15 dez. 2006.

McCLAUGHRY, J. Milton Friedman responds. Business and Society Review, New York: Blackwell, n. 1, spring, 1972.

RAMANATHAN, K. Toward a theory of corporate social accounting. The Accounting Review, v. 51, n. 3, p. 516-528, July, 1976.

SANTOS, A. Demonstração do valor adicionado: como elaborar e analisar a DVA. São Paulọ: Atlas, 2003.

SOCIAL ACCOUNTABILITY INSTTITUTE - SAI. SA 8000 Certification. Disponível em: <http://www.sa-intl.org/>: Acesso em: 17 dez. 2006. STEVENSON, W. J. Estatística aplicada à administração. São Paulo: Harbrạ, 1981.

TINOCO, J. E. P. Balanço social: uma abordagem da transparência e da responsabilidade pública das organizações. São Paulo: Atlas, 2001. TIPGOS, M. A. Toward a theory of corporate social accounting: a comment. The Accounting Review, v. 52, n. 4, p. 977-983, October, 1977. ULLMANN, A. A. The academy of management review, v. 10, n. 3, p. 540-557, 1985.

WADDOCK, S. Integrity and mindfulness: foundations of corporate citizenship. In: ANDRIOF, J. (ed.). Perspectives on corporate citizenship. Sheffield: Greanleaf, p. 26-38, 2001

WOOD, D. J. Corporate social performance revisited. Academy of Management Review, v.16, n. 4,p. 691-718, 1991.

\section{NOTA - Endereço dos autores}

Universidade Presbiteriana Mackenzie

NETS - Núcleo de Estudos do Terceiro Setor

R. da Consolação, 900

Ed. Modesto Carvalhosa - $6^{\circ}$ andar - sala 602

São Paulo - SP

01302-907 